\title{
STUDY OF MATERNAL MORTALITY IN A TERTIARY CARE CENTRE
}

\section{Gynaecology}

Anamika* SENIOR RESIDENT, Deptt. of OBG, P.M.C.H, Patna. *Corresponding Author

Amrita Sharan

PROFESSOR, Deptt. of OBG, P.M.C.H, Patna.

\section{ABSTRACT}

Background: Maternal death or maternal mortality is defined by the World Health Organisation (WHO) as the "death of a women while pregnant or within 42 days of termination of pregnancy, irrespective of the duration and site of pregnancy, from any cause related to or aggravated by the pregnancy or its management but not from accidental or incidental causes.'

Aims And Objectives:

1. To study the causes of maternal mortality,

2. To identify the deficits to decrease the current rate of maternal mortality.

Materials And Methods: This was a retrospective study done by analyzing hospital records of maternal mortality occurring in the department of obstetrics and gynaecology of a tertiary care hospital of Bihar from January 2019 to December 2019.

Results: A total of 126 deaths occurred in this period of 1 year. The total number of live births was 5568 in this year making the maternal mortality rate (MMR) to be 2262.93. This may be due to the fact that being a referral institute most of the cases were referred from the peripheries. $76.19 \%$ of the women were referred from outside. The most common age group to be affected was 20 to 29 years (79.36\%). Multiparous women were more affected than primiparous women $(61.9 \% \mathrm{~V} / \mathrm{s} 38.10 \%)$. The most common cause of maternal mortality was eclampsia seen in $26.98 \%$ cases followed by PPH seen in $22.22 \%$ cases, anemia in $8.73 \%$, medical complications in $7.94 \%$ cases , APH in $7.14 \%$ cases , rupture uterus in $7.14 \%$ cases. The most common type of delay was type 1 and 2 . More number of women were from rural areas. More number of women were illiterates. Most of the women had no ANC.

Conclusion: Illiteracy, poverty, lack of knowledge, delayed referrals, lack of ANC are major contributing factors causing such high maternal mortality rate. Health education, strengthening of peripheral health care and availability of trained health workers and essential drugs should be enforced.

\section{KEYWORDS}

Maternal mortality, eclampsia, anemia, haemorrhage.

\section{INTRODUCTION}

"Every minute a woman dies as a result of pregnancy or childbirth"(1). Maternal mortality ratio(MMR) is number of maternal deaths during given time per 100,000 live births during the same period. MMR in the world's least developed countries is high. Nigeria and India had the highest estimated number of maternal deaths, accounting for approximately one third (35\%) of estimated global maternal deaths in 2017 with India accounting for 35000 maternal deaths $(12 \%$ of global maternal deaths).Despite the ambition to end preventable maternal deaths by 2030 ,the world will fall short of this target by more than 1 million lives with current pace of progress. Hence, there is a continued urgent need for maternal health and survival to remain high (2).

According to the International Classification of Diseases (ICD), $10^{\text {th }}$ revision, maternal death is classified using two main categories: direct and indirect maternal death(1).

Direct obstetric deaths are those resulting from obstetric complications of the pregnant state(i.e. pregnancy, labour and the puerperium), from interventions, omissions or incorrect treatment, or from a chain of events resulting from any of the above. Indirect obstetric deaths are those resulting from a previously existing disease or a disease that developed during pregnancy and which was not due to direct obstetric cause but which was aggravated by the physiological effects of pregnancy. Discriminating between the two may be difficult at times and misclassification can occur. The only concrete way of determining the cause of death is by autopsy, which is not a viable option for most resource poor countries(3)

In developing countries, the most common causes of direct maternal death are haemorrhage, sepsis, pregnancy induced hypertension and complications of unsafe abortion while the most common causes of indirect maternal death are anemia, HIV/AIDS and malaria(4).

Maternal mortality in a resource poor nations has been attributed to the "3 delays"-delay to seek care, delay in reaching care in time, and delay in receiving adequate treatment(5). These can be classified as type 1,2, 3 type of delays respectively(6).

Though India has shown 61\% drop in maternal mortality rate between 2000 and 2017 making its MMR 145 in 2017, the SDG (sustainable development goal ) is to reduce the MMR to 70 per 100000 live births by $2030(2)$

\section{AIMS AND OBJECTIVES}

1. To study the causes of maternal mortality,

2. To identify the deficits to decrease the current rate of maternal mortality.

\section{MATERIALS AND METHODS \\ Type OfStudy}

This was a retrospective observational study.

\section{Method OfStudy}

It was done by analyzing patient's medical records from hospital's medical record department of maternal mortality occurring in the department of Obstetrics and Gynaecology of a tertiary care hospital of Bihar.

\section{Period OfStudy}

January 2019 to December 2019.

\section{Inclusion Criterion}

All cases of maternal mortality due to direct and indirect cause, occurring during pregnancy or 42 days of its termination including abortion and ectopic pregnancy.

\section{Exclusion Criterion}

All cases of maternal mortality due to accidental causes like physical trauma or burn.

\section{Statistical Tool}

Microsoft excel

\section{RESULTS}

A total of 126 deaths occurred in this period of 1 year. The total number of live births were 5568 in this year making the maternal mortality rate (MMR) to be 2262.93 per 1 lakh live births.

The most common age group to be affected was 25 to 29 years (42.86\%).12.70\% women were of age group 20 -24 years, $8.73 \%$ women belonged to 35-39 years age group. Lesser women were affected in 30-34 year age group (5.56\%) and less than 19 years age group $(3.97 \%)$.Least common age group to be affected was greater than 40 years $(2.38 \%)$. (Table 1$)$

$61.9 \%$ of multiparous women were affected and $38.10 \%$ of 
primiparous women were affected .(Figure 1)

Table 1. Age Distribution Of Cases Of Maternal Mortality.

\begin{tabular}{|l|l|l|}
\hline Age Group(years) & Number $(\mathbf{n}=\mathbf{1 2 6})$ & Percentage $(\mathbf{\%})$ \\
\hline$<=19$ & 5 & 3.97 \\
\hline $20-24$ & 46 & 12.7 \\
\hline $\mathbf{2 5 - 2 9}$ & $\mathbf{5 4}$ & $\mathbf{4 2 . 8 6}$ \\
\hline $30-34$ & 7 & 5.56 \\
\hline $35-39$ & 11 & 8.73 \\
\hline$>=40$ & 3 & 2.38 \\
\hline
\end{tabular}

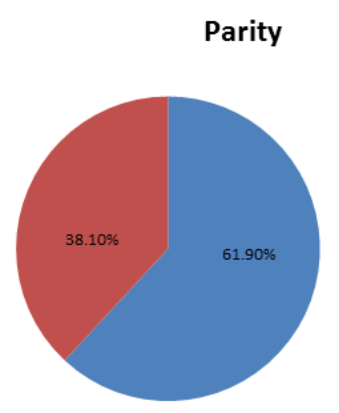

= MULTIPAROUS - PRIMIPAROUS

Figure 1: Parity Distribution Of Maternal Mortality.

A total of 96 cases out of 126 were referred from other health facilities. Only 30 cases were admitted primarily at our institute.(Table 2)

Table 2: Referral Pattern Of Maternal Mortality.

\begin{tabular}{|l|l|l|}
\hline Referred & Number $(\mathrm{n}=126)$ & Percentage $(\%)$ \\
\hline Yes & $\mathbf{9 6}$ & $\mathbf{7 6 . 1 9}$ \\
\hline No & 30 & 23.81 \\
\hline
\end{tabular}

Direct cause of maternal mortality was more common than indirect cause $(80.96 \% \mathrm{v} / \mathrm{s} 19.04 \%)$. Overall hypertensive disorders of pregnancy was the most common cause of maternal mortality $(26.19 \%)$ followed by haemorrhage(23.01\%).

Individually, eclampsia was the most common cause of maternal mortality $(24.60 \%)$ followed by Primary PPH(15.1\%), anemia(11.11\%), rupture uterus $(7.14 \%)$, placenta praevia $(5.56 \%)$ and sepsis $(3.97 \%)$.(Table 3$)$

Table 3: Cause Distribution Of Maternal Mortality

\begin{tabular}{|l|l|l|}
\hline Cause & Number(n=126) & Percentage(\%) \\
\hline $\begin{array}{l}\text { Hypertensive disorders } \text { of } \\
\text { pregnancy }\end{array}$ & $\mathbf{3 3}$ & $\mathbf{2 6 . 1 9}$ \\
\hline 1.Preeclamsia & 2 & 1.59 \\
\hline 2. Eclampsia & $\mathbf{3 1}$ & $\mathbf{2 4 . 6 0}$ \\
\hline Hemorrhage & 29 & 23.01 \\
\hline 1.Placenta praevia & 7 & 5.56 \\
\hline 2.Abruptio placentae & 2 & 1.59 \\
\hline 3.PPH & 20 & 15.87 \\
\hline & 19 & 15.1 \\
\hline \multicolumn{1}{|c|}{ b.Primary Secondary } & 1 & 0.79 \\
\hline Anemia & 14 & 11.11 \\
\hline Rupture uterus & 9 & 7.14 \\
\hline Sepsis & 5 & 3.97 \\
\hline Heart disease & 4 & 3.17 \\
\hline Blood reaction & 4 & 3.17 \\
\hline DIC & 4 & 3.17 \\
\hline Obstructed labour & 3 & 2.38 \\
\hline Pulmonary edema & 3 & 2.38 \\
\hline Hepatitis & 3 & 2.38 \\
\hline Ruptured ectopic pregnancy & 2 & 1.59 \\
\hline HELLP syndrome & 2 & 1.59 \\
\hline Post op complications & 2 & 1.59 \\
\hline TB & 2 & 1.59 \\
\hline Inversion uterus & 1 & 0.79 \\
\hline Amniotic fluid embolism & 1 & 0.79 \\
\hline Peripartum cardiomyopathy & 1 & 0.79 \\
\hline Pulmonary embolism & 1 & 0.79 \\
\hline Aspiration & & \\
\hline & 1 & \\
\hline & 1 & \\
\hline & 1 & \\
\hline
\end{tabular}

\begin{tabular}{|l|l|l|}
\hline Anaesthetic complications & 1 & 0.79 \\
\hline Asthma & 1 & 0.79
\end{tabular}

The most common type of delay was type 2( $58.73 \%$ ). Type 1 delay was seen in $4.76 \%$ and type 3 delay was seen in $36.5 \%$.(Figure 2 )

\section{DELAYS}

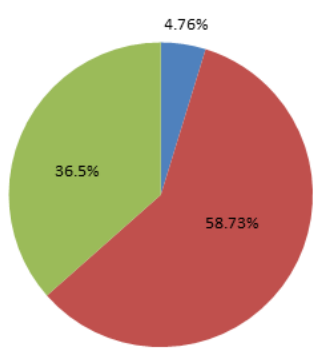

= Type 3

Figure 2: Type Of Delays Causing Maternal Mortality

Most of the women died within 24 hours of admission $76(60.32 \%)$.Others died by 1 to 3 days $27(21.49 \%)$, 3days to 1 week $17(13.50 \%)$ and greater than 1 week $6(4.76 \%)$

102 out 126 women were from rural areas (80.95\%) and 24 women were from urban areas(19.05\%).(Figure 3)

\section{Residential distribution}

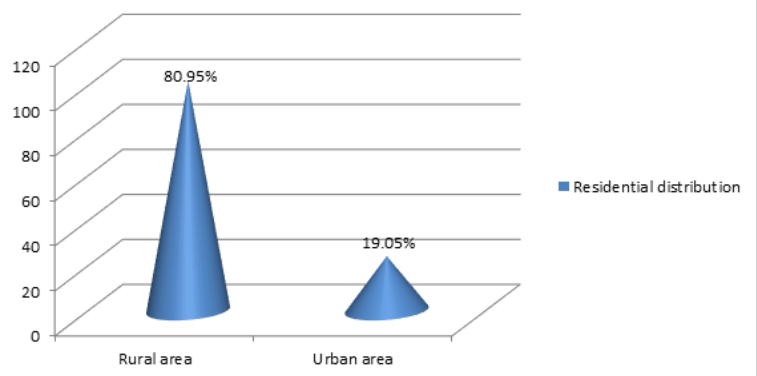

56 of 126 women were illiterates(44.44\%) and 53 were only literate(42.03\%). And only $13.50 \%$ had some form of education.

Most of the women had no ANC. Only 6 out of $126(4.76 \%)$ sufficed the WHO criterion of minimum ANCs. Rest 120 (95.24\%) had no ANC or inadequate $\mathrm{ANC}$

\section{DISCUSSION}

The MMR of 2262.93 per 1 lakh live births is very high but this may be due to the fact that being a referral institute most of the cases were referred in complicated state from $\mathrm{PHCs}$, sadar hospitals, private institutions etc. In study done at same institute by Singh $\mathrm{R}$ et al the MMR was 3906.44 per 1 lakh livebirths(7).

$76.19 \%$ of these cases were referred from other health facilities. And only $23.81 \%$ cases were primarily seeking care at our institute. The referral rate was similar to study done by Neha Agarwal et al in a 6 year retrospective study in a tertiary care hospital $(75.6 \%)(8)$. Inspite of being referred to these well established tertiary care centre patients are unable to survive as they reach late and are already in moribund state, irreversible shock ,coma, multiple organ failure state etc. which are beyond the point of reversal.

Most $(60.32 \%)$ women died in less than 24 hours of admission. And maximum of them were referred after multiple eclamptic fits or massive primary PPH. Gaikwad NB et al also found in his study that maximum mortality occurred within 24 hours of admission(9).

The most common age group to be affected was $25-29$ years $(42.86 \%)$ followed by $20-24$ years $(12.70 \%$ ) making $20-30$ years age group to be most affected $(55.56 \%)$. This was similar to study done by Singh R et $\mathrm{al}(56.54 \%)$ and Baul et al $(51.8 \%)(7,10)$. Agarwal $\mathrm{N}$ et al and Kumari JS et al also found this group to be most affected but with higher percentage of involvement of $78.8 \%$ and $71.4 \%$ respectively $(8,11)$ And also in their studies showed more involvement in 21-25 year subgroup. This may be due to cultural differences in age of marriage. 
Multiparous women were more affected than primiparous women $(61.9 \% \mathrm{v} / \mathrm{s} 38.10 \%)$.Multigravida women are more susceptible to increased bleeding due to PPH and also due to severe uncorrected anemia due to frequent childbirths. And most often such women belong to lower socioeconomic class with malnutrition and no ANCs. This finding was similar to study done by Singh R et al $(75.08 \%)$, Agarwal $\mathrm{N}$ et $\mathrm{al}(60 \%)$ and Sultan et al $(55.31 \%)(7,8,12)$. However, Kumari JS et al found that primiparous women were more affected $(61.9 \%)(11)$

Most of these women came from rural areas (80.95\%). This was similar to study by Singh R et al $(67.17 \%)$ and Gaikwad NB et al $(87.3 \%)(7,9)$. $44.44 \%$ were illiterates and $42.03 \%$ were only literate with no form of basic education and hence hardly knew anything about reproductive health.

Most of the women (95.24\%) had no ANC or inadequate ANC making them far from ANC facilities and health education.

The most common cause of death was hypertensive disorders of pregnancy $(26.19 \%)$ out of which eclampsia was alone responsible in $24.60 \%$ cases. This was similar to finding by Singh R et al(24.01\%), Shabana et al(39.64\%), and Bhaskar et al(26.66\%).(7,12,13). Preeclampsia can easily be detected early and managed to prevent eclampsia and other fatal complications. Even many deaths from eclampsia can be prevented by timely administration of magnesium sulphate.

The second most common cause of maternal mortality was haemorrhage $(23.01 \%)$. Similar findings were seen in studies by Shabana et al(18.93\%), Bhaskar et al(26.66\%) and Vidhya et al $(21 \%)(12,13,14)$. Primary PPH was causative agent in $15.1 \%$ cases which can easily be prevented and managed. Placenta praevia caused mortality in $5.56 \%$ cases which could have been timely intervened if emergency obstetric care services have been available in the remote areas.

The third most common cause of maternal mortality was anemia seen in $11.11 \%$. This is also a preventable cause. In other studies similar percentage was seen- Singh R et al $(15.81 \%)$, Shabana et al $(8.58 \%)$ and Bhaskar et $\mathrm{al}(10 \%)(7,12,13)$

The fourth most common rupture uterus seen in $7.14 \%$ women . This is a growing problem due to increasing trend of caesarian deliveries and lack of birth spacing.

The fifth common cause was Sepsis and was seen in $3.97 \%$ cases. Study by Singh R et al (2003-2005) show sepsis to be second commonest (17.93\%)(7). Study by Shabana et al(2007 to 2011) show it to be fourth commonest $(7.39 \%)(12)$. The lesser percentage may be due to advent of stronger antibiotics and more skilled deliveries.

The most common type of delay was type 2 seen in $58.73 \%$ cases. Despite of Government's provision of free transportation for pregnant women, this delay was commonest most probably due to multiple referrals or lack of awareness. Type 3 delay was seen in $36.5 \%$ cases due to multiple referrals and lack of specialized obstetric facilities at previous centres. Type 1 delay was seen in $4.76 \%$ which is due to ignorance and illiteracy.

\section{CONCLUSION}

Availabilty of (skilled birth attendents, drugs like iron, oxytocics and magnesium sulphate, blood products), strengthening BMOC / EMOC facilities, health education and awareness are need of hour. Every women and her family should understand the importance of ANC. Contraceptive practices should be promoted for birth spacing and unwanted pregnancies. Timely and linked referrals between the 3 levels of healthcare will save many lives.

\section{REFERENCES}

1. WHO, UNICEF, UNFPA.Maternal mortality in 2000:Estimates developed by WHO,UNICEF,UNFPA.Geneva:WHO,2003

2. Trends in Maternal Mortality 2000 to 2017 :estimates by WHO, UNICEF, UNFPA, World Bank, United Nations Population Division. Geneva: World Health Organisation;2019. License:CC BY-NC-SA3.0 IGO.

3. Kuo AM, Haukoos JS, Witt MD, Babaie ML, Lewis RJ. Recognition of undiagnosed HIV infection:an evaluation of missed oppurtunities in a predominantly urban minority population. AIDS Patient Care STDS 2005; 19:239-46

4. Khan KS, Wojdyla D, Say L, Gulmezoglu AM, Van Look PF. WHO analysis of causes of maternal death: a systematic review. Lancet 2006;367:1066-74.

5. Maternal United Nations Population Fund(UNFPA), authors Maternal Mortality Update
2002: AFocus on Emergency Obstetric Care.Newyork:UNFPA;2003.

6. Thaddeus S, Maine D. Too far to walk: maternal mortality in context. Soc Sci Med 1994;38:1091-1100.

7. Singh R, Sinha N, Bhattacharyya K, Ram R. Pattern of maternal mortality in a Tertiary Care Hospital of Patna, Bihar: Indian J Med.2009;34:73-4

8. Agarwal N, Chaudhari HK, Audit on maternal mortality in a tertiary care centre in India of 6 years, a retrospective analysis. Int J Reprod Contracept obstet Gyneco 2020;9:xxx_xx.

9. Gaikwad NB, Poornima M, Lad RM. A retrospective study of maternal mortality in a tertiary care hospital in Western Maharashtra, India. Int J Res Med Sci 2020;8:1796-801.

10. Baul MK, Manjusha Maternal mortality : A ten year study. J Indian Med Assoc.2004;102:18-9.

11. Kumari JS, Revathi V, Reddy KS.A study of maternal mortality in Government Maternity Hospital, Sri Venkateswara Medical College, Tirupati. Indian J Obstet Gynecol Res. 2018;5(4):525-529.

12. Sultan S, kumar A, Bhagchandani D, Dhingre H. Analysis of Maternal Mortality in a tertiary care centre: A 5 year retrospective study. Journal of Evolution of Medical and Dental Sciences.2013;2:1730-1737.

13. Murthy BK, Murthy MB, Prabhu PM. Maternal mortality in a tertiary care hospital: A ten year review. Int J Prev Med 2013;4:105-9.

14. Vidyadhar B. Bangal, Purushottam A. Giri, Ruchika Garg. Maternal Mortality at tertiary Care teaching hospital of rural India; A retrospective study. Int J Biol Med Res.2011;2(4):1043-1046. 